Интернет-журнал «Науковедение» ISSN 2223-5167 http://naukovedenie.ru/

Выпуск 6 (25) 2014 ноябрь - декабрь http://naukovedenie.ru/index.php?p=issue-6-14

URL статьи: http://naukovedenie.ru/PDF/55EVN614.pdf

DOI: 10.15862/55EVN614 (http://dx.doi.org/10.15862/55EVN614)

\title{
УДК 368
}

\begin{abstract}
Аллабян Карен Джанович
Центральный банк Российской Федерации

Россия, Москва ${ }^{1}$

Заведующий сектором контроля процедур восстановления платежеспособности Аспирант Финансового университета при Правительстве РФ

E-Mail: artist100@bk.ru
\end{abstract}

\section{Регулирование и надзор на страховом рынке: системный аспект}

Аннотация. В статье представлено детальное исследование понятий регулирование, надзор и страховой рынок при продолжающихся процессах реорганизации органа страхового надзора в Российской Федерации в условиях нестабильности на финансовых рынках.

Автор, используя системный подход, провел анализ существующей модели страхового надзора, определил место страхового надзора в системе государственного регулирования страхового рынка и представил внутреннею и внешнею среду функционирования страхового рынка.

Проведенный автором анализ и исследование позволило считать доказанным правомерность рассмотрения страхового надзора как системы.

Ключевые слова: Страховой рынок; система; экономическая система; внешняя среда страхового рынка; элементы системы страхового рынка; государственное регулирование страховой деятельности; системный анализ; подсистема страхового рынка; системный подход; страховой надзора; признаки системы.

Ссылка для цитирования этой статьи:

Аллабян К.Д. Регулирование и надзор на страховом рынке: системный аспект // Интернет-журнал «НАУКОВЕДЕНИЕ» 2014. № 6 http://naukovedenie.ru/PDF/55EVN614.pdf (доступ свободный). Загл. с экрана Яз. рус., англ. DOI: 10.15862/55EVN614

${ }^{1}$ ул. Неглинная, 12, Москва, 107016 
Страховой рынок как систему определяет большинство изданий, посвященных вопросам страхования. В частности, «Словарь страховых терминов» дает такое определение: «Рынок страховой - система экономических отношений, возникающих по поводу куплипродажи специфического товара «страховое покрытие» в процессе удовлетворения общественных потребностей в страховой защите. Рынок страховой возникает в условиях множественности страховщиков (продавцов специфического товара «страховое покрытие»), выступающих независимыми, имущественно обособленными организациями, аккумулирующими страховой фонд». Страховой рынок как систему определяет и большинство ученых, занимающихся проблемами страхования.

Руководствуясь логикой системного подхода, определяющей, что: «...система является экономической, если она предназначена для переработки вещества, энергии, информации и знаний в потребительские стоимости или обеспечивает их распределение, обмен и потребление», а также приведенным определением страхового рынка, можно сделать вывод о том, что страховой рынок является экономической системой.

Классификация экономических систем, позволяющая позиционировать каждую экономическую систему в пространстве и во времени, выделяет в качестве классов такие системы, как:

$$
\begin{array}{ll}
\text { - } & \text { проектные; } \\
\text { - } & \text { объектные; } \\
\text { - } & \text { процессные; } \\
\text { средовые. }
\end{array}
$$

В соответствии с этой классификацией как средовую систему можно рассматривать фондовый рынок, рынок трудовых ресурсов и др. В их числе и страховой рынок. Миссия последнего заключается в создании условий для обмена финансовыми ресурсами, информацией и знаниями между различными экономическими субъектами с целью предоставления страховой защиты.

Для гармоничного развития экономики необходимо, чтобы в ней поддерживался постоянный паритет экономических систем всех четырех классов. Нарушение пропорций порождает дисгармонию, которая может перерасти в кризис. Следствием дисфункции средовых систем является фрагментация экономики и разрыв хозяйственных связей. Следовательно, страховой рынок, являясь экономической средовой системой, оказывает влияние на соблюдение необходимых в экономической системе пропорций.

При исследовании любой системы ее целостность и обособленность обычно рассматриваются как внешние свойства. Более детальное рассмотрение ее «внутренности» позволяет разбить систему на составные компоненты меньшего размера. Те части системы, которые рассматриваются как неделимые, называются элементами, а части, состоящие более чем из одного элемента, называют подсистемами.

Анализируя экономическую систему, следует исходить из того, что:

1) она является открытой системой, существующей во внешней среде и взаимодействующей с ней;

2) ее элементы также могут быть рассмотрены как системы;

3) любая экономическая система создается, существует и развивается для удовлетворения потребностей систем более высокого уровня.

Следуя этой логике, можно сделать выводы: 
- $\quad$ страховой рынок как система существует и развивается для удовлетворения потребности национальной экономики - системы более высокого уровня - в защите от воздействия неблагоприятных факторов, способных замедлить (нарушить) процессы общественного воспроизводства;

- $\quad$ внешней средой страхового рынка является экономика страны, т.е. страховой рынок можно рассматривать как элемент систем более высокого уровня, в т.ч. национальной экономики;

- $\quad$ элементы системы страхового рынка могут быть рассмотрены в качестве его подсистем.

Вышесказанное позволяет представить внутреннюю и внешнюю среду функционирования страхового рынка (рисунок 1).

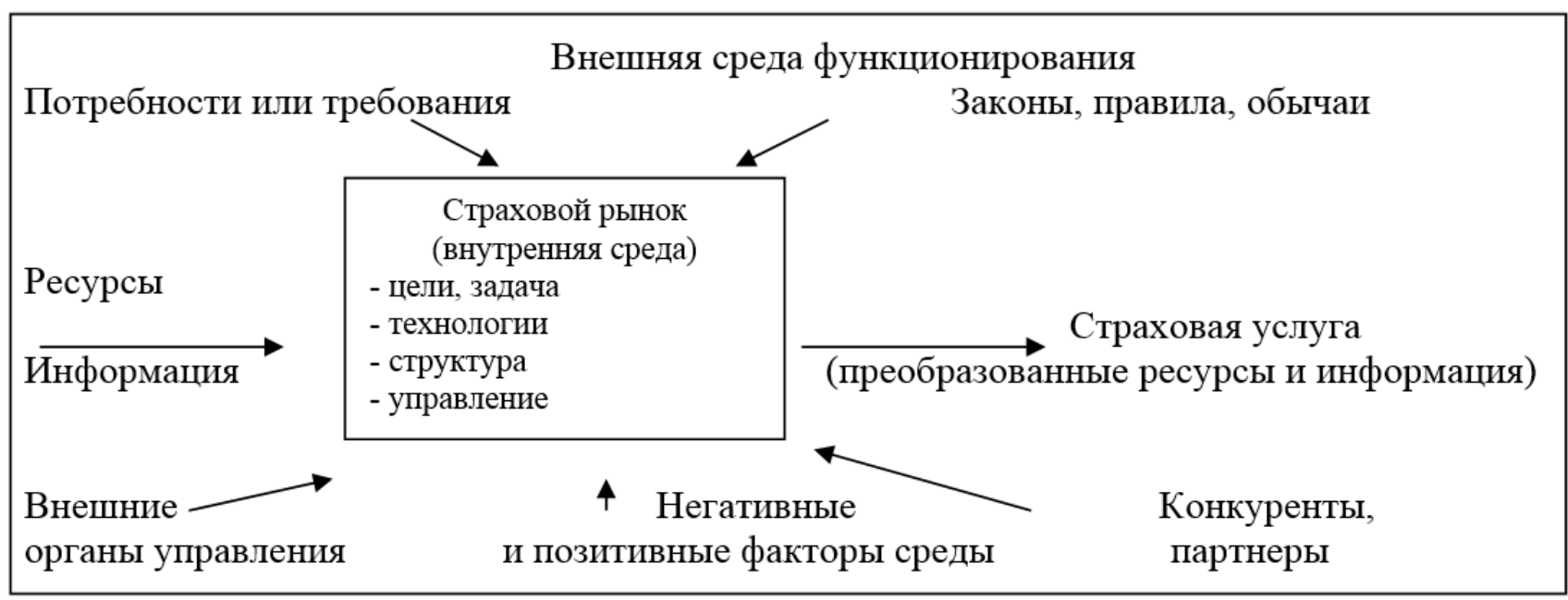

Рисунок 1. Взаимодействие страхового рынка с его внешней средой

Составлено автором

Отметим, что институционально в состав страхового рынка входят субъекты и объекты страховых правоотношений, что позволяет некоторым исследователям определять страховой рынок как «национальную систему страхования».

С точки зрения реализации отношений между элементами внутри системы «страховой рынок» можно выделить:

- отношения между страхователями и страховщиками;

- отношения между страховщиками и их объединениями;

- отношения между страхователями и государством, а также страховщиками (объединениями страховщиков) и государством.

Структурируя названные группы отношений по уровням их реализации, можно определить страховой рынок как систему макроуровня (при этом он по-прежнему является подсистемой национальной экономики), а объединения страховых организаций (видовые, территориальные) и страховые организации - как подсистемы страхового рынка на мезо- и микроуровнях соответственно. 


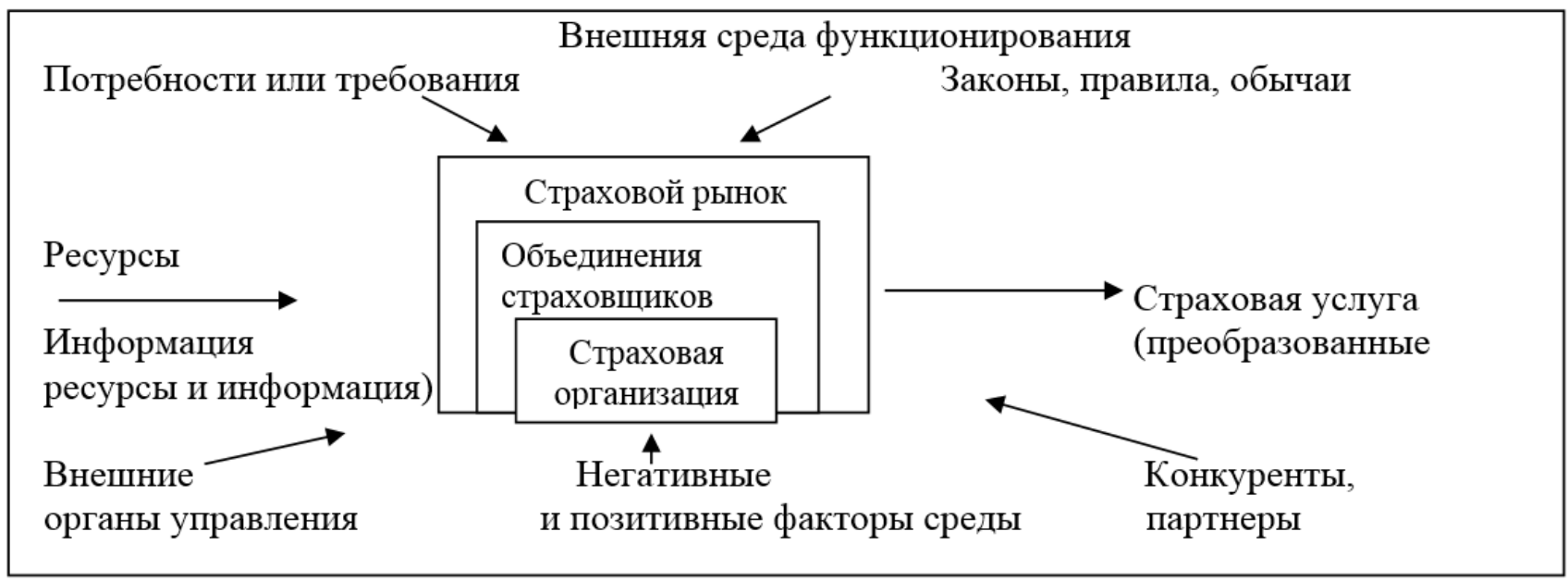

Рисунок 2. Взаимодействие страхового рынка с внешней средой по уровневой организации отношений внутри системы

\section{Составлено автором}

Управление данной системой осуществляется государством путем создания специального механизма - государственного регулирования, представляющего собой совокупность методов, форм и экономических инструментов регулирования для обеспечения развития страхового рынка. Системный подход позволяет рассматривать государственное регулирование как подсистему системы «страховой рынок».

Элементы страхового рынка объединены в определенную структуру, в рамках которой они взаимодействуют между собой. Модель государственного регулирования системы «страховой рынок» свидетельствует, исходя из числа и разнообразия отношений между элементами, о сложности системы (рисунок 3 ).

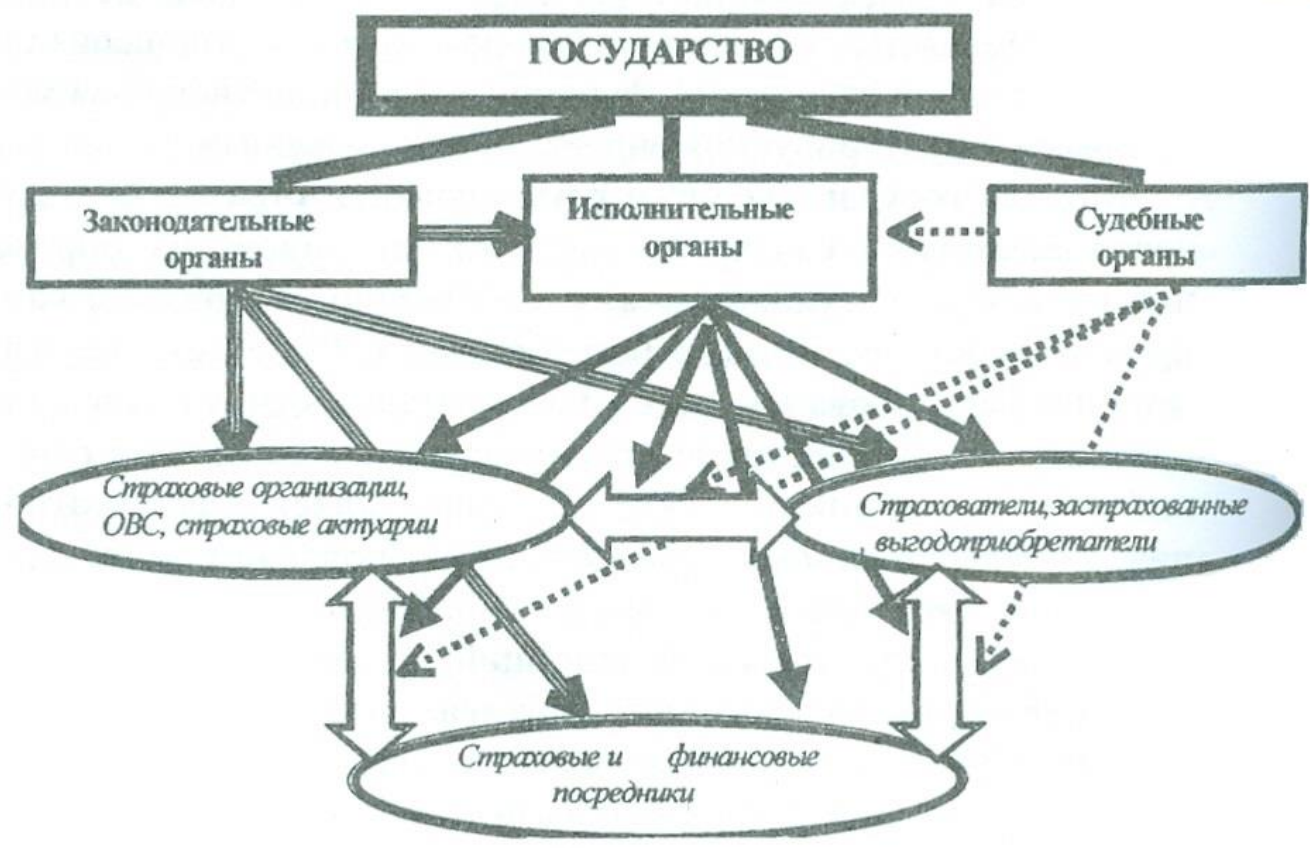

Рисунок 3. Модель государственного регулирования страховой деятельности.

Источник заимствования:

Жилкина М.С. Государственное регулирование. -М.: «Спутник»+», 2002. -301. 
Государственное регулирование страховой деятельности объективно необходимо, что объясняется: «...отсутствием совершенной конкуренции и неспособностью достичь полного равновесия на рынке, несовершенством информации, в силу чего наличием высоких трансакционных издержек, проблемой общественных товаров и необходимостью распределения, а также влиянием внешних факторов и необходимостью обеспечения безопасности государства».

Государственное регулирование страховой деятельности осуществляется по следующим направлениям:

- $\quad$ принятие законодательных актов в области страхования, а также в других сферах деятельности, касающихся страхования;

- организация обязательных видов страхования, осуществляемых в интересах общества;

- $\quad$ проведение специальной налоговой политики, предоставление налоговых льгот страхователям и/или страховщикам с целью стимулировать развитие определенных видов страхования;

- надзор за функционированием страховых организаций, страховых брокеров, обществ взаимного страхования и других субъектов страхового дела.

Каждое из названных направлений можно рассматривать как подсистему государственного регулирования страховой деятельности, поскольку оно:

a) является ее частью, и взаимодействуя с другими частями позволяет системе поддерживать свое существование и функционировать как единое целое;

б) включает в себя ряд элементов системы, что позволяет, руководствуясь приемами системного анализа, объединять их в подсистемы.

Из вышесказанного следует:

1. Страховой рынок, являясь открытой социально-экономической системой, может рассматриваться не только как элемент системы более высокого порядка - национальной экономики, но и как внешняя среда для систем более низкого уровня. Последние могут быть рассмотрены как его подсистемы.

2. Подсистемы страхового рынка могут быть структурированы в зависимости как от уровня входящих элементов (страховые организации, их объединения, общества взаимного страхования и др.), так и от выполняемых подсистемой функций (управление, контроль, надзор и т.д.).

3. Государственное регулирование страховой деятельности является подсистемой страхового рынка и внешней средой страхового надзора, который следует рассматривать как подсистему регулирования страхового рынка (рисунок 4). 


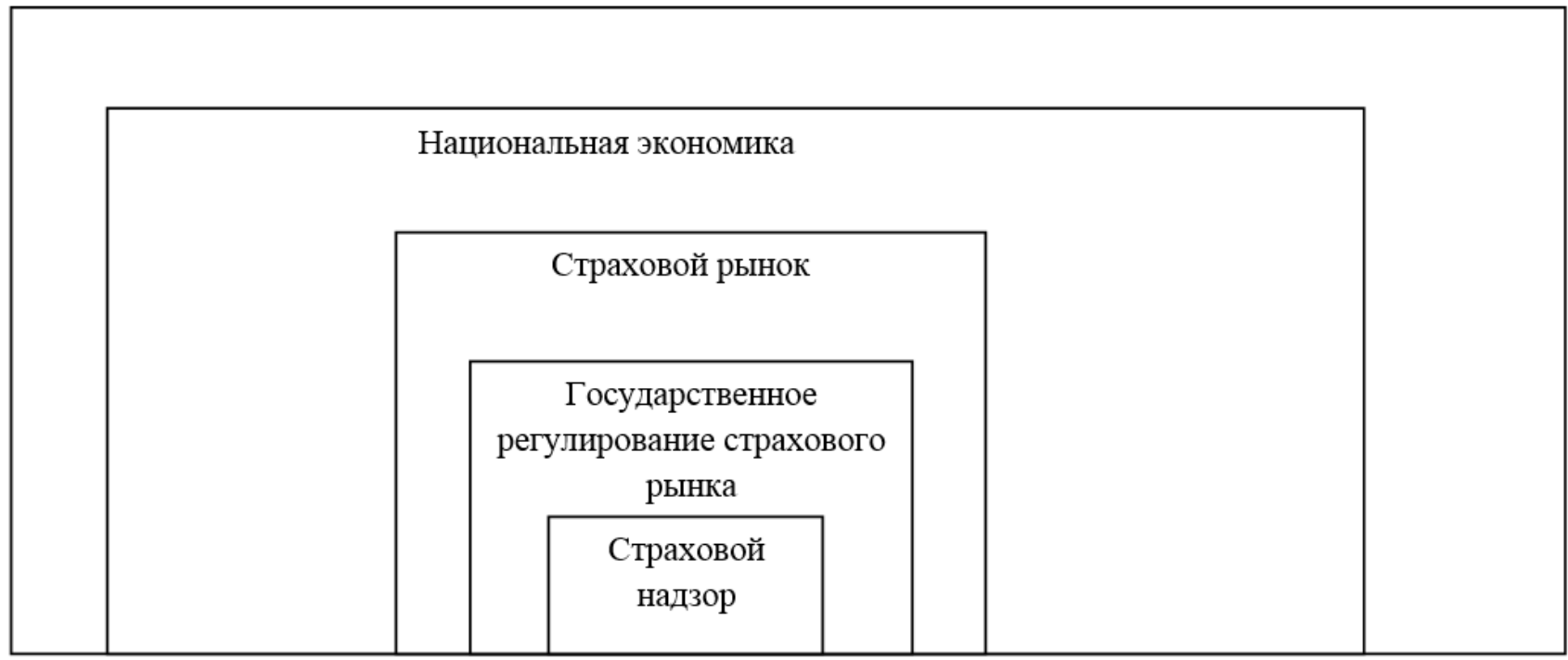

Рисунок 4. Место страхового надзора в системе государственного регулирования страхового рынка

С одной стороны, системный подход позволяет рассматривать страховой надзор как подсистему государственного регулирования страховых отношений в обществе. С другой стороны, страховой надзор представляет собой совокупность методов, форм и экономических инструментов, т.е. элементов системы, обеспечивающих «...соблюдение субъектами страхового дела законодательства, защиту прав и законных интересов страхователей... и государства, эффективного развития страхового дела».

В отечественной теории и практике словосочетание «система страхового надзора» вполне устойчиво и применимо, однако четкого научного обоснования пока не получило. Одни авторы [Юргенс] применяли системный подход к страхованию в целом, вводя понятие «национальная система страхования» и не рассматривая ее отдельные подсистемы, другие [Бакиров, Клинич] рассматривали национальную экономику как макросистему рынка услуг (в т.ч. страховых).

В монографии Р.Т. Юлдашева, Л.И. Цветковой словосочетания «системный анализ», «системный подход» активно используются, однако системные признаки страхового надзора не рассматриваются.

В труде В.К. Райхера «Общественно-исторические типы страхования» страховой надзор обозначен как «...форма государственной активности и выделено три системы надзора: 1) система публичности; 2) нормативная система; 3) система материального надзора. «Первая из этих трех систем довольствуется публикацией и представлением в соответствующие государственные органы отчетов и балансов страховых обществ. Вторая - устанавливает определенные условия возникновения и деятельности страховых обществ. Третья - дает органам государственного надзора право проверять не только формальное выполнение этих условий, но и самую деятельность страхового общества по существу как с финансовой, так и с оперативно-технической стороны». Таким образом, под системами страхового надзора автор понимает лишь объем полномочий, которыми законодательно наделен надзорный орган.

Вышесказанное свидетельствует об актуальности научного обоснования понятия «система страхового надзора».

Для научного обоснования страхового надзора как системы следует, прежде всего, определить понятие «система». Специалисты системного анализа в экономике отмечают, что существует несколько десятков определений системы, которые в большей или меньшей 
степени довольно точно фиксируют ее отдельные характеристики, но «...не находят однозначного признания научной общественностью. Таким образом, на сегодня теория систем остается без общепринятого определения своего объекта». Если же исходить из понимания системы, как «...нечто целого, представляющего собой единство закономерно расположенных и находящихся во взаимной связи частей», а также из того, что сущность явления обычно раскрывают через описание его характерных свойств попытаемся доказать системность страхового надзора через выявление его системных признаков.

Специалисты в области системного анализа выделяют несколько признаков системы так называемых системных свойств, основными из которых являются структурированность, эмерджентность, иерархичность, устойчивость. Рассмотрим эти свойства на примере страхового надзора.

Структурированность как свойство системы предполагает объединение элементов системы в определенную структуру, в рамках которой они взаимодействуют между собой. Элементы системы - субъект и объекты надзора - объединяет страховой рынок, участниками институционального состава которого они являются и в рамках которого осуществляется их взаимодействие. Следовательно, структурированность как свойство системы, присуще страховому надзору.

Свойство эмерджентности, или эффекта системы, предполагает обладание системой свойств, не присущих ее компонентам, а также их простой сумме. Это системное свойство присуще страхового надзору, что подтверждается следующим: объекты надзора, в первую очередь, страховые организации, являются коммерческими предприятиями и нацелены на получение прибыли. Субъект надзора призван обеспечить соблюдение законодательства субъектами страхового дела, защиту законных интересов страхователей и государства. Системный эффект проявляется в том, что, несмотря на разнонаправленность целей, при взаимодействии элементов системы осуществляется реализация страховой защиты и страхования как способа управления рисками.

Иерархичность как свойство предполагает, что каждая система является элементом системы более высокого порядка. Можно говорить, что системы «вложены» одна в другую как матрешки. Страховой надзор является подсистемой государственного регулирования, а регулирование - подсистемой страхового рынка (рисунок 4). Таким образом, иерархичность характерна для системы страхового надзора.

Устойчивость любой системы является непременным условием ее существования и позволяет ей функционировать в изменяющейся внешней среде. История становления и развития современной системы страхового надзора в РФ, начавшаяся в 1991 году и продолжающаяся в наше время, свидетельствует не только о постоянной необходимости совершенствования, но и об устойчивости ее основных позиций.

Вышесказанное позволяет считать доказанным правомерность рассмотрения страхового надзора как системы, поскольку страховой надзор:

a) является составной частью системы регулирования, включает в себя ряд элементов этой системы. Это позволяет исследовать страховой надзор как подсистему системы государственного регулирования страхового рынка;

б) рассмотрение признаков, характерных для любой системы структурированность, эмерджентность, иерархичность, устойчивость подтверждает их присутствие у страхового надзора и также дает основание определить страховой надзор как систему. 
Система страхового надзора является подсистемой регулирования страхового рынка, при этом может рассматриваться как самостоятельная система контроля за функционированием субъектов страхового дела с целью защиты прав и законных страхователей и государства.

Дальнейшее исследование системы страхового надзора требует рассмотрения вопросов ее организации и функционирования на российском и международном страховых рынках.

\section{ЛИТЕРАТУРА}

1. Закон Российской Федерации от 28.11.1992 № 4015-1 «Об организации страхового дела в Российской Федерации».

2. Федеральный закон от 27.10.2002 № 127-Ф3 «О несостоятельности (банкротстве).

3. Аллабян К.Д. Методика оценки финансового состояния страховщика-члена саморегулируемой организации в рамках надзора за его деятельностью со стороны само-регулируемой организации//Интернет-журнал «Науковедение», 2013 № 6 (11) [Электронный ресурс]-М.: Науковедение, 2013.

4. С.Е. Кован. Теория антикризисного управления социально-экономическим системами. Ресурсный подход. М, ИНФРА-М, 2013, стр. 15-16.

5. Райхер В.К. «Общественно-исторические типы страхования» Из-во Академии наук СССР. М., Л., 1947, стр. 149-150.

6. И.Н. Дрогобыцкий. Системный анализ в экономике. Уч-к. ЮНИТИ М, 2012, стр. 64.

7. Г.А. Насырова. Теория и практика государственного регулирования страховой деятельности. Москва, 2012, стр. 154.

8. Клейнер Г.Б. Ресурсная теория системной организации экономики.// Российский журнал менеджмента. 2011. Т9 № 3. С. 328.

9. Словарь страховых терминов. Под ред. Е.В. Коломина, В.В. Шахова, М., Финансы и статистика, 1992, стр. 192.

10. С.И. Ожегов. Словарь русского языка. Москва «Русский язык», 1988, стр. 586.

Рецензент: Бабич Сергей Александрович, начальник отдела Банка России, кандидат экономических наук. 


\author{
Allabyan Karen Djanovich \\ Central Bank of the Russian Federation \\ Moscow, Russian Federation \\ E-Mail: artist100@bk.ru
}

\title{
Regulation and supervision on the insurance market: the system aspect
}

\begin{abstract}
The article presents a detailed study of the concepts of regulation, supervision and the insurance market in the ongoing processes of reorganization of the insurance Supervisory authority in the Russian Federation in the conditions of instability in the financial markets. The author, using a systematic approach, conducted an analysis of existing models of insurance supervision, determined the place of insurance supervision in the system of state regulation of the insurance market and presented internal and external environment of the insurance market. Conducted by the author of the analysis and the study allowed us to consider the legitimacy of the review of the insurance supervision system.

Keywords: Insurance market; system; economic system; the external environment of the insurance market; the elements of the system of the insurance market; state regulation of insurance activity; system analysis, subsystem of the insurance market; the system approach; the insurance supervision; the characteristics of the system.
\end{abstract}




\section{REFERENCES}

1. Zakon Rossiyskoy Federatsii ot 28.11.1992 № 4015-1 «Ob organizatsii strakhovogo dela v Rossiyskoy Federatsii».

2. Federal'nyy zakon ot 27.10.2002 № 127-FZ «O nesostoyatel'nosti (bankrotstve).

3. Allabyan K.D. Metodika otsenki finansovogo sostoyaniya strakhovshchika-chlena samo-reguliruemoy organizatsii v ramkakh nadzora za ego deyatel'nost'yu so storony samo-reguliruemoy organizatsii//Internet-zhurnal «Naukovedenie», 2013 № 6 (11) [Elektronnyy resurs]-M.: Naukovedenie, 2013.

4. S.E. Kovan. Teoriya antikrizisnogo upravleniya sotsial'no-ekonomicheskim sistemami. Resursnyy podkhod. M, INFRA-M, 2013, str. 15-16.

5. Raykher V.K. «Obshchestvenno-istoricheskie tipy strakhovaniya» Iz-vo Akademii nauk SSSR. M., L., 1947, str. 149-150.

6. I.N. Drogobytskiy. Sistemnyy analiz v ekonomike. Uch-k. YuNITI M, 2012, str. 64.

7. G.A. Nasyrova. Teoriya i praktika gosudarstvennogo regulirovaniya strakhovoy deyatel'nosti. Moskva, 2012, str. 154.

8. Kleyner G.B. Resursnaya teoriya sistemnoy organizatsii ekonomiki.// Rossiyskiy zhurnal menedzhmenta. 2011. T9 № 3. S. 328.

9. Slovar' strakhovykh terminov. Pod red. E.V. Kolomina, V.V. Shakhova, M., Finansy i statistika, 1992, str. 192.

10. S.I. Ozhegov. Slovar' russkogo yazyka. Moskva «Russkiy yazyk», 1988, str. 586. 